\title{
$\alpha 2 \delta$-1 Signaling in Nucleus Accumbens Is Necessary for Cocaine-Induced Relapse
}

\author{
(1) Sade Spencer, ${ }^{1}$ Robyn M. Brown, ${ }^{1,4}$ Gabriel C. Quintero, ${ }^{1,2,3}$ Yonatan M. Kupchik, ${ }^{1}$ Charles A. Thomas, ${ }^{1}$ \\ Kathryn J. Reissner, ${ }^{1,5}$ and Peter W. Kalivas ${ }^{1}$ \\ ${ }^{1}$ Department of Neurosciences, Medical University of South Carolina, Charleston, South Carolina 29425, ${ }^{2}$ Florida State University-Panama, Clayton, \\ Republic of Panama, ${ }^{3}$ Institute of Scientific Research and High Technology Services, Center for Neurosciences, Clayton, Republic of Panama, ${ }^{4}$ Florey \\ Institute of Neuroscience and Mental Health, University of Melbourne, Parkville, Victoria 3052, Australia, and ${ }^{5}$ University of North Carolina at Chapel Hill, \\ Chapel Hill, North Carolina 27599-9100
}

Relapse to cocaine seeking is associated with potentiated excitatory synapses in nucleus accumbens. $\alpha_{2} \delta$ - 1 is an auxiliary subunit of voltage-gated calcium channels that affects calcium-channel trafficking and kinetics, initiates extracellular signaling cascades, and promotes excitatory synaptogenesis. Previous data demonstrate that repeated exposure to alcohol, nicotine, methamphetamine, and morphine upregulates $\alpha_{2} \delta$-1 in reward-related brain regions, but it was unclear whether this alteration generalized to cocaine. Here, we show that $\alpha_{2} \delta$-1 protein was increased in nucleus accumbens after cocaine self-administration and extinction compared with saline controls. Furthermore, the endogenous ligand thrombospondin-1, responsible for the synaptogenic properties of the $\alpha_{2} \delta$-1 receptor, was likewise elevated. Using whole-cell patch-clamp recordings of EPSCs in nucleus accumbens, we demonstrated that gabapentin, a specific $\alpha_{2} \delta$-1 antagonist, preferentially reduced the amplitude and increased the paired-pulse ratio of EPSCs evoked by electrical stimulation in slices from cocaine-experienced rats compared with controls. In vivo, gabapentin microinjected in the nucleus accumbens core attenuated cocaine-primed but not cue-induced reinstatement. Importantly, gabapentin's effects on drug seeking were not due to a general depression of spontaneous or cocaine-induced locomotor activity. Moreover, gabapentin had no effect on reinstatement of sucrose seeking. These data indicate that $\alpha_{2} \delta$-1 contributes specifically to cocaine-reinstated drug seeking, and identifies this protein as a target for the development of cocaine relapse medications. These results also inform ongoing discussion in the literature regarding efficacy of gabapentin as a candidate addiction therapy.

Key words: $\alpha 2 \delta$-1; cocaine self-administration; gabapentin; nucleus accumbens; relapse; thrombospondin

\section{Introduction}

Even after prolonged abstinence, drug users experience high rates of relapse (Dennis and Scott, 2007). Pathological alterations in physiological and structural plasticity mediated by enduring changes in glutamatergic transmission are key features underlying vulnerability to relapse (Kalivas, 2009; Wolf, 2010; Gipson et al, 2013). Hence, investigation of mechanisms responsible for this plasticity represents a priority of preclinical research. Voltage-gated calcium channels (VGCCs) control neurotransmitter release, influence neuronal excitability, regulate gene transcription, and participate in multiple forms of short-term plasticity, underscoring their importance in regulating normal neurotransmission (Kawamoto et al., 2012). Moreover, VGCCs

Received March 18, 2013; revised May 14, 2014; accepted May 19, 2014.

Author contributions: S.S., R.M.B., Y.M.K., K.J.R., and P.W.K. designed research; S.S., R.M.B., G.C.Q., Y.M.K., C.A.T., and K.J.R. performed research; S.S., G.C.Q., Y.M.K., and K.J.R. analyzed data; S.S. and P.W.K. wrote the paper.

This work was supported by NIH Grant DA015369/DA003906 (P.W.K.). R.M.B. was supported by the American Australian Association. The authors thank members of the Kalivas laboratory for helpful comments on a previous version of this manuscript.

The authors declare no competing financial interests.

Correspondence should be addressed to Sade Spencer, Medical University of South Carolina, 173 Ashley Avenue, BSB 403, Charleston, SC 29425. E-mail: spences@musc.edu.

DOI:10.1523/JNEUROSCI.1204-13.2014

Copyright $\odot 2014$ the authors $\quad 0270-6474 / 14 / 338605-07 \$ 15.00 / 0$ have been implicated in drug-related plasticity and behavior. Repeated noncontingent cocaine administration increases voltage-sensitive calcium currents in response to membrane depolarization in medial prefrontal cortex, an effect reversed by an L-type calcium channel (LTCC) antagonist (Nasif et al., 2005); and the development and expression of cocaine locomotor sensitization is dependent on VGCC function (Pierce et al., 1998; Schierberl et al., 2011).

VGCCs are heteromeric complexes comprised of a poreforming $\alpha_{1}$ subunit with ancillary $\beta, \alpha_{2} \delta$, and $\gamma$ subunits (Dolphin, 2012). $\alpha_{2} \delta-1$ modulates VGCC kinetic properties, including inactivation rate, in addition to regulating channel trafficking and stability (Dolphin, 2012). Moreover, $\alpha_{2} \delta$ - 1 subunits perform calcium-independent functions, including intracellular or extracellular signaling and excitatory synaptogenesis. While a number of reports have examined the involvement of individual $\alpha_{1}$ subunits to drug-induced plasticity and reward, much less is known about the contributions of accessory subunits. Repeated, noncontingent treatment with nicotine, ethanol, and methamphetamine increases $\alpha_{2} \delta$ - 1 in cerebral cortex (Hayashida et al., 2005; Katsura et al., 2006; Kurokawa et al., 2011). Preliminary results from a proteomic screen indicate that $\alpha_{2} \delta$-1 is upregulated in NAc postsynpatic density (PSD)-enriched subfraction 
from cocaine self-administering animals, compared with saline controls, raising the possibility that $\alpha_{2} \delta-1$ is also regulated by cocaine and by both contingent and noncontingent drug administration (Reissner et al., 2011).

Gabapentin (GBP, Neurontin), an antiepileptic approved by the U.S. Food and Drug Administration, is a high-affinity ligand for $\alpha_{2} \delta-1$ (Gee et al., 1996). Chronic gabapentin reduces calcium currents via inhibition of $\alpha_{2} \delta$-1 membrane trafficking, its purported primary mechanism of action in neuropathic pain. Effects of acutely applied gabapentin on calcium currents are more equivocal with some reports of inhibition and others showing no effect (Uchitel et al., 2010). Gabapentin acting on presynaptic $\alpha_{2} \delta$-1-containing VGCCs reduces the release of many neurotransmitters and neuromodulators, explaining its indirect effects on GABAergic transmission and misleading nomenclature (Uchitel et al., 2010). Moreover, gabapentin directly antagonizes thrombospondin (TSP)-mediated excitatory synapse formation (Eroglu et al., 2009). Astrocyte-secreted TSP proteins are endogenous ligands for $\alpha_{2} \delta$-1 whose binding promotes excitatory synapse formation independent of calcium-channel activity (Eroglu et al., 2009). The present study sought to verify the proteomic identification of upregulated $\alpha_{2} \delta-1$ as a consequence of cocaine self-administration, and uses gabapentin as a selective $\alpha_{2} \delta$-1 antagonist in NAc core (NAcore) to demonstrate functional involvement of upregulated $\alpha_{2} \delta$-1 in cocaine reinstatement and cocaine-induced cellular adaptations.

\section{Materials and Methods}

Animals. Single-housed male Sprague Dawley rats (225-250 g) purchased from Charles River Laboratories were acclimated to facilities 1 week before surgery. Subjects were kept on a $12 \mathrm{~h}$ reverse light/dark cycle. Standard chow and water was provided ad libitum before self-administration; however, food was restricted to $\sim 20 \mathrm{~g} / \mathrm{d}$ throughout behavioral testing. Procedures were preapproved by the Institutional Animal Care and Use Committee at Medical University of South Carolina and performed in compliance with National Institutes of Health guidelines.

Surgery. Rats were anesthetized with ketamine $\mathrm{HCl}(87.5 \mathrm{mg} / \mathrm{kg}$ of Ketaset, Fort Dodge Animal Health)/xylazine ( $5 \mathrm{mg} / \mathrm{kg}$ Rompum, Bayer) and implanted with intrajugular catheters and 26 gauge bilateral guide cannulas (Plastics One) in NAcore: $+1.5 \mathrm{~mm}$ anteroposterior, $+2.0 \mathrm{~mm}$ mediolateral, $-5.0 \mathrm{~mm}$ dorsoventral (Paxinos and Watson, 2005). Ketorolac $(3 \mathrm{mg} / \mathrm{kg}$ ) was given postoperatively for analgesia. Prophylactic antibiotic (cefazolin $10 \mathrm{mg} / 0.1 \mathrm{ml}$, i.v.) was administered during surgery and $5 \mathrm{~d}$ postoperatively.

Self-administration. Catheters were flushed daily with heparin to maintain patency. Rats acquired operant responding for food pellets in one $15 \mathrm{~h}$ overnight session on a fixed-ratio (FR) 1 schedule before beginning $2 \mathrm{~h}$ daily self-administration sessions. Rats self-administered cocaine until reaching a criterion of $10 \mathrm{~d} \geq 10$ infusions $(0.2 \mathrm{mg} / 0.05 \mathrm{ml})$, followed by 2 weeks extinction as described previously (Reissner et al., 2011). Training was performed in standard operant chambers containing a house light, drug-paired tone and cue light, and two retractable levers (Med Associates). Yoked-saline controls received a saline infusion for each cocaine infusion. During extinction, active lever presses no longer resulted in delivery of cocaine or cues. Cue-induced reinstatement entailed the drug-free reintroduction of previously drug-paired light/tone cues contingent upon lever pressing. Cocaine-primed reinstatement was precipitated by a $10 \mathrm{mg} / \mathrm{kg}$ intraperitoneal cocaine injection without cues.

Western blotting. Animals were rapidly decapitated and tissue samples microdissected for sample preparation. PSD subcellular fractionation samples were homogenized with $0.32 \mathrm{~m}$ sucrose, 10 mM HEPES, $\mathrm{pH} 7.4$, and protease/phosphatase inhibitor mixture (Thermo Fisher Scientific). The PSD was isolated as a Triton X-100-insoluble fraction as described previously (Reissner et al., 2011). Whole-cell lysates were prepared in RIPA buffer supplemented with $1 \%$ SDS and inhibitors. Immunoblot- ting was performed according to standard protocols (Reissner et al., 2011). Primary antibodies were used as follows: $\alpha_{2} \delta$-1 (Sigma-Aldrich \#D219; 1:2000), ADAMTS1 (Abcam \#39194; 1:1000), TSP-1 (Dr. Dean Mosher, University of Wisconsin-Madison; 1:500), GAPDH (Cell Signaling Technology \#2118; 1:5000).

Whole-cell patch-clamp recordings. NAcore medium spiny neurons (MSNs) were whole-cell patch clamped as described before (Kupchik et al., 2012). Briefly, acute coronal brain slices were prepared using a Leica VT1200S vibratome (Leica Microsystems) and kept in room temperature aCSF (in mm: $126 \mathrm{NaCl}, 1.4 \mathrm{NaH}_{2} \mathrm{PO}_{4}, 25 \mathrm{NaHCO}_{3}, 11$ glucose, 1.2 $\mathrm{MgCl}_{2}, 2.4 \mathrm{CaCl}_{2}, 2.5 \mathrm{KCl}, 2.0 \mathrm{Na}$-pyruvate, $0.4 \mathrm{~L}$-ascorbic acid, bubbled with $95 \% \mathrm{O}_{2}$ and $5 \% \mathrm{CO}_{2}$ ) containing $5 \mathrm{~mm}$ kynurenic acid and $50 \mu \mathrm{M}$ D-(-)-2-amino-5-phosphonopentanoic acid until recording. Recordings were performed at $32^{\circ} \mathrm{C}$ (TC-344B; Warner Instrument) in dorsomedial NAcore using glass microelectrodes (1-2 M $\Omega$ ) containing (in mM) 124 cesium methanesulfonate, 10 4-(2-hydroxyethyl)-1-piperazineethanesulfonic acid potassium, 1 ethylene glycol tetraacetic acid, $1 \mathrm{MgCl}_{2}, 10 \mathrm{NaCl}, 2$ magnesium adenosine triphosphate, 1 QX-314, $\mathrm{pH}$ 7.2-7.3, 272-275 mOsm. EPSCs were evoked with a bipolar stimulating electrode (FHC) $\sim 200 \mu \mathrm{m}$ dorsomedial to recording electrode, amplified by a Multiclamp 700B amplifier (Molecular Devices), and recorded using Axograph software (Axograph Scientific). Each trace consisted of two identical stimulations $50 \mathrm{~ms}$ apart to provide the paired-pulse ratio (PPR). Recordings were collected every $30 \mathrm{~s}$. GABA-evoked inhibitory currents were blocked by $50 \mu \mathrm{M}$ picrotoxin. Series resistance $\left(R_{\mathrm{s}}\right)$ was monitored with a $-2 \mathrm{mV}$ test pulse and recordings with unstable $R_{\mathrm{s}}\left(20 \%\right.$ change) or $R_{\mathrm{s}}>20 \mathrm{M} \Omega$ were discarded.

Sucrose self-administration and reinstatement. The parameters for sucrose self-administration were similar to those for cocaine. Rats learned to respond for sucrose pellets paired with light and tone cues on progressively increasing schedules (FR1, FR2, FR5) until they stabilized their responding on a FR5 schedule. Rats then entered 2 weeks extinction wherein lever pressing had no consequence. During reinstatement, subjects received two pellets immediately on session initiation and an additional 10 pellets at $2 \mathrm{~min}$ intervals for the first $20 \mathrm{~min}$ of the session. Lever presses resulted in cue but not sucrose delivery.

Microinjections and histology. Gabapentin (Sigma-Aldrich) or aCSF was microinjected into NAcore ( $2 \mathrm{~mm}$ below the guide cannula base) before reinstatement. Microinjection $(0.5 \mu$ l total volume) occurred over a $2 \mathrm{~min}$ period followed by $2 \mathrm{~min}$ diffusion time. Reinstatement was initiated after 10 min delay. Rats were tested in a random, crossover design separated by $2-3$ d of extinction for both within-subject and between-subjects comparisons. For histology, animals were overdosed with sodium pentobarbital $(100 \mathrm{mg} / \mathrm{kg}$, i.p. $)$ and transcardially perfused with $1 \times$ PBS followed by $4 \%$ paraformaldehyde. Coronal sections (100 $\mu \mathrm{m})$ were stained with cresyl violet to validate cannula placement.

Locomotor activity. Rats were placed in a photocell apparatus to record movement using software that estimated distance traveled based on consecutive breaking of adjacent photobeams for $60 \mathrm{~min}$ to assess effects of gabapentin on exploratory/basal locomotor activity (AccuScan Instruments). Effects of gabapentin on cocaine-induced activity $(10 \mathrm{mg} / \mathrm{kg}$, i.p.) were assessed after $1 \mathrm{~h}$ habituation to chambers. Rats received microinjections of gabapentin/aCSF into NAcore immediately before placement in photocell chambers.

Statistics. Electrophysiological and behavioral data were analyzed by ANOVA followed by a Bonferroni's or Dunnet's post hoc test for multiple comparisons. When only two groups were compared, as in Western blotting, statistical probability was determined by two-tailed Student's $t$ test. Between-subjects analysis was conducted for cue-induced reinstatement due to ordering effect.

\section{Results}

$\alpha_{2} \delta$-1 Protein is upregulated after cocaine self-administration We performed Western blotting on a membrane-enriched fraction and whole-cell lysates from NAcore comparing rats after cocaine self-administration and extinction with saline controls to validate a suggested increase in calcium-channel subunit $\alpha_{2} \delta$-1 from a proteomic screen (Reissner et al., 2011). $\alpha_{2} \delta$-1 levels were 

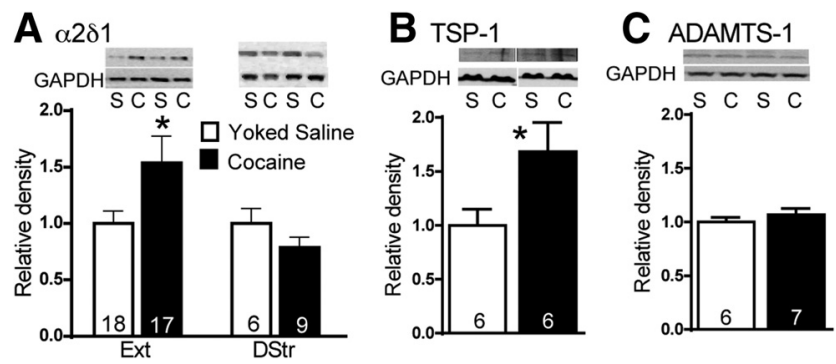

Figure 1. Cocaine self-administration upregulates $\alpha_{2} \delta-1 . A, \alpha_{2} \delta-1$ is increased after cocaine self-administration (C) compared with saline (S) in PSD subfractions and whole-cell lysates (left). $\alpha_{2} \delta-1$ was unchanged in the dorsal striatum at this time point (right). $B$, TSP-1 was elevated after extinction from cocaine self-administration compared with saline. $C$, ADAMTS-1 was unaltered by cocaine self-administration. Data shown as relative density to yoked-saline values, and $N$ is shown in the bars.

greater in cocaine-extinguished rats than in controls in NAcore (Fig. $1 A ; t_{(33)}=2.087,{ }^{\star} p=0.045$ ). We examined $\alpha_{2} \delta$ - 1 in dorsal striatum because of concerns that microinjected GBP might diffuse back up the cannula track into dorsal striatum in our behavioral assays, but found no difference between cocaine and yoked-saline animals (Fig. 1A) nor any effect of GBP on reinstated cocaine seeking when directly administered dorsal to NAcore (see Fig. 4). We concurrently assessed whether cocaine experience affected the levels of TSP-1, an endogenous secreted ligand for $\alpha_{2} \delta-1$, and found an increase in TSP-1 after self-administration and extinction (Fig. $1 B ; t_{(10)}=2.214,{ }^{*} p=$ $0.05)$. Given the potential importance of post-translational processing of TSP-1, we assessed levels of ADAMTS1 (A disintegrin and metalloprotease with thrombospodin type 1 motifs), which cleaves TSP-1, releasing the C-terminal tails from the trimeric $\mathrm{N}$-terminal domain (Lee et al., 2006), but observed no change in ADAMTS-1 levels (Fig. 1C).

\section{Gabapentin reduced evoked EPSC amplitude and increased PPR}

To examine the effects of gabapentin on cocaine-induced synaptic plasticity, we performed whole-cell patch-clamp recordings of NAcore MSNs from cocaine-extinguished and yoked-saline rats. Bath application of $50 \mu \mathrm{m}$ gabapentin decreased evoked EPSC amplitude normalized as a percentage of pregabapentin baseline amplitude in cocaine but not saline rats (Fig. 2A, B; paired Student's, $\left.t_{(8)}=3.38, p<0.001\right)$. These data are consistent with a functional increase in $\alpha_{2} \delta$-1 protein after cocaine self-administration and extinction. Additionally, gabapentin increased the PPR in cocaine rats (Fig. $2 A, C$; paired Student's, $t_{(8)}=2.83, p=0.022$ ), suggesting presynaptic inhibition of glutamate release.

\section{Gabapentin inhibited cocaine-primed but not cue-}

\section{induced reinstatement}

Next we examined whether pharmacological antagonism of the $\alpha_{2} \delta$-1 subunit with gabapentin affects cocaine reinstatement. Rats were trained to self-administer cocaine to criterion $(\sim 12 \mathrm{~d})$, then extinguished for an additional 12-16 d (Fig. 3A). Initial studies using dual cocaine plus cue-primed reinstatement showed a dose-dependent effect of gabapentin on reinstatement response (Fig. 3B; one-way ANOVA with repeated measures, $F_{(3,58)}=$ $22.43, p<0.001$; Fig. $3 C$, guide cannula placements). Importantly, the lower $10 \mu \mathrm{g}$ gabapentin dose did not modify basal locomotor activity or the acute locomotor stimulating effects of cocaine $(10 \mathrm{mg} / \mathrm{kg}$, i.p.; Fig. $4 A)$. The $33 \mu \mathrm{g}$ gabapentin dose showed no effect on baseline locomotor activity; however, it sig-
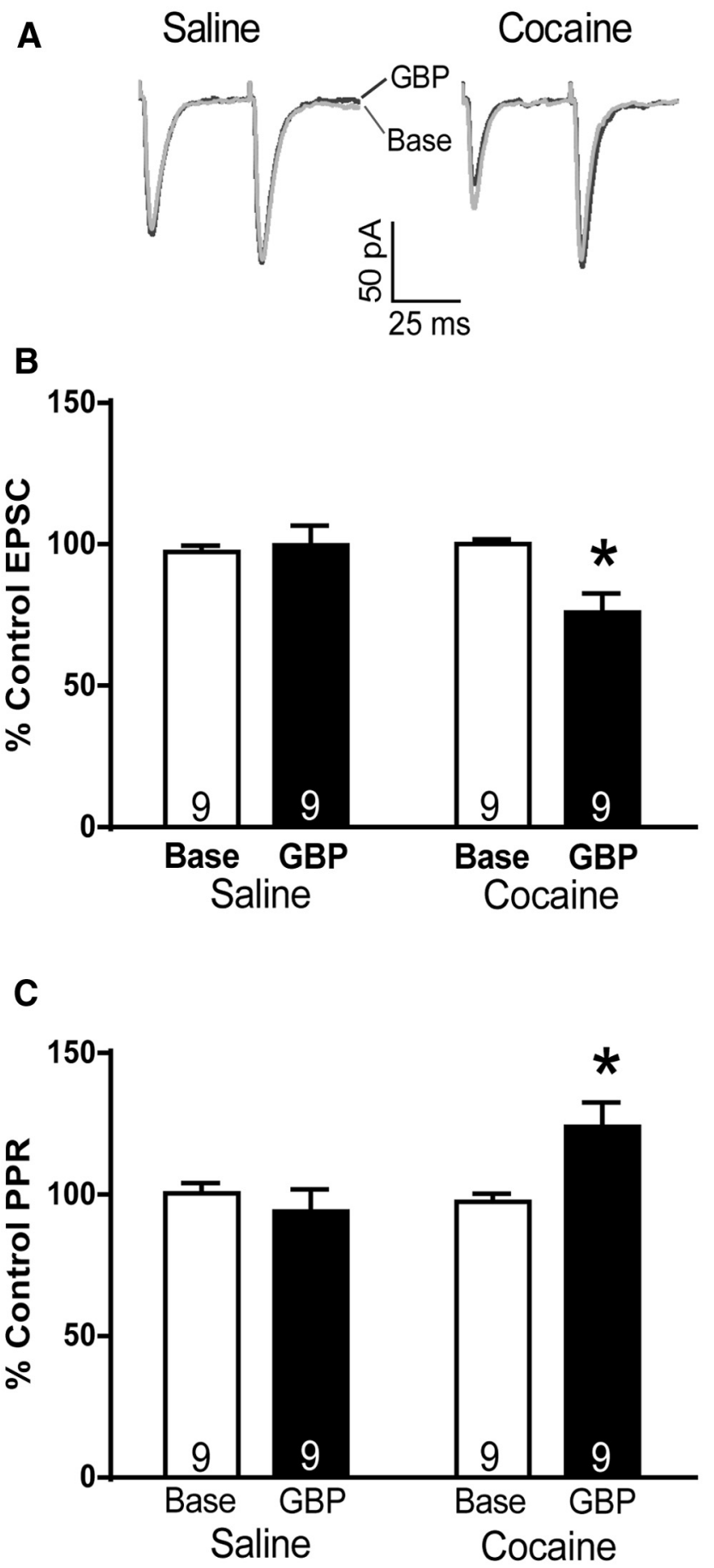

Figure 2. Gabapentin reduces evoked EPSC amplitude and increases PPR. $A$, Representative traces of evoked EPSC recorded from NAcore MSNs of yoked-saline (left) and cocaineextinguished (right) rats before and after washing with $50 \mu \mathrm{m}$ gabapentin. $\boldsymbol{B}$, Gabapentin decreased EPSCs only in cocaine-extinguished rats. $C$, Gabapentin increased PPR only in cocaine-extinguished rats. ${ }^{*} p<0.05$, comparing effect of GBP with baseline.

nificantly attenuated cocaine-induced locomotor activity, necessitating the use of the $10 \mu \mathrm{g}$ dose in subsequent experiments (Fig. $4 B$; repeated-measures two-way ANOVA, interaction $F_{(23,460)}=$ $3.67, p<0.001)$.

Because divergent neuronal mechanisms may underlie the distinct modalities of reinstatement (cue-induced vs drugprimed; Shaham et al., 2003; Epstein et al., 2006), we used a separate cohort of rats to query gabapentin's effects on each form 

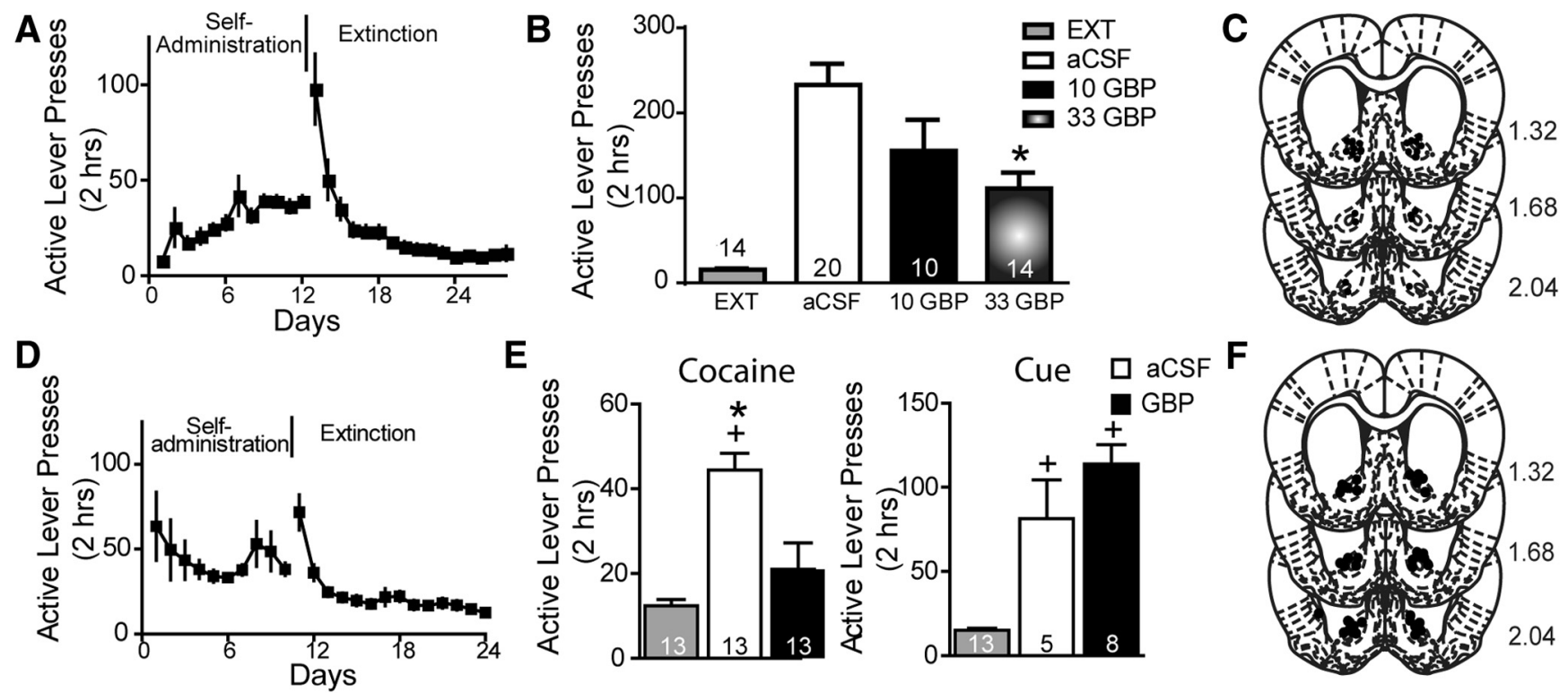

Figure 3. Gabapentin attenuates cocaine-induced reinstatement. $\boldsymbol{A}$, Active lever pressing during self-administration and extinction training corresponding to data in $\boldsymbol{B}$. $\boldsymbol{B}$, Microinjection of gabapentin into the NAcore dose-dependently reduced cocaine plus cue reinstatement compared with vehicle. EXT, Average active lever presses over the $2 \mathrm{~d}$ of extinction before each reinstatement trial. $\boldsymbol{C}$, Histological verification of injection sites corresponding to data in $\boldsymbol{B}$; numbers are millimeters rostral to bregma. $\boldsymbol{D}$, Active lever pressing during self-administration and extinction training corresponding to data in $\boldsymbol{E}$. $\boldsymbol{E}$, Gabapentin (10 $\mu \mathrm{g} /$ side) significantly reduced cocaine-primed reinstatement (left) but had no impact on cue-induced reinstatement (right). $\boldsymbol{F}$, Histological verification of injection sites corresponding to data in $\boldsymbol{E}$. $+p<0.05$ compared with extinction levels of active lever pressing using a Bonferroni's post hoc analysis. ${ }^{*} p<0.05$, comparing aCSF to gabapentin.

of reinstatement independently. Rats similarly underwent cocaine self-administration and extinction (Fig. 3D). Using the previously validated $10 \mu \mathrm{g}$ dose, we found that gabapentin significantly decreased cocaine seeking elicited by a noncontingent cocaine priming injection (Fig. $3 E$, left; one-way ANOVA with repeated measures, $\left.F_{(2,23)}=22.55, p<0.001\right)$. In contrast, gabapentin was ineffective at altering cue-induced reinstatement (Fig. 3E, right; one-way ANOVA between subjects, $F_{(2,23)}=$ $32.55, p<0.001$; Fig. $3 F$, guide cannula placements). When one or both of the injector tips was located outside of the NAcore, generally just dorsal to the boundary, the effect of gabapentin on cocaine-primed reinstatement was lost (Fig. 4C-E). Importantly, in sucrose self-administration controls, gabapentin likewise had no effect on pellet plus cue-primed reinstatement (Fig. $4 F-H$ ).

\section{Discussion}

Here we show that VGCC $\alpha_{2} \delta$-1 subunit is elevated in NAcore after cocaine self-administration and extinction. While we cannot rule out an influence by extinction training, the two other studies found elevated $\alpha_{2} \delta$ - 1 at $24 \mathrm{~h}$ after a final noncontingent daily drug injection (methamphetamine or nicotine), suggesting that the increase may not depend on extinction training or a withdrawal period (Hayashida et al., 2005; Kurokawa et al., 2011). In agreement with elevated $\alpha_{2} \delta$-1 levels, cocaineextinguished rats were more sensitive to the EPSC-inhibiting effects of gabapentin. Additionally, the levels of $\alpha_{2} \delta$ - 1 ligand TSP- 1 were increased after cocaine. When $\alpha_{2} \delta$-1 was acutely antagonized with gabapentin, there was a decrease in cocaine-primed reinstatement with no effect on reinstatement of a natural reward, sucrose. These results point to a pivotal role for elevated $\alpha_{2} \delta$-1 in cocaine-reinstated drug seeking, an animal model of relapse (Shaham et al., 2003).

This is the first report directly targeting drug-induced $\alpha_{2} \delta-1$ in a brain region critical to reward during reinstatement. Notably, the possibility that altered $\alpha_{2} \delta$-1 function is a shared neuropathology in addiction is indicated by the fact that it is increased by chronic noncontingent treatment with other classes of addictive drug (Hayashida et al., 2005; Kurokawa et al., 2011). $\alpha_{2} \delta$-1 Interacts with multiple subtypes of voltage-sensitive calcium channels, including presynaptic release-regulating $\mathrm{N}$-type and P/Q-type channels, as well as with postsynaptic L-type channels, which have been implicated in animal models of addiction (Rajadhyaksha and Kosofsky, 2005; Dolphin, 2012). In association with presynaptic VGCCs, $\alpha_{2} \delta$-1-inhibiting gabapentinoid drugs decrease evoked release of many neurotransmitters, including glutamate and dopamine (Reimann, 1983; Quintero et al., 2011). Corticoaccumbens glutamate transmission is increased during reinstated cocaine seeking (Kalivas, 2009), and the GBP-induced decrease in eEPSCs and increase in PPR in NAcore MSNs of cocaine animals supports this presynaptic mechanism. Alternatively, GBP also reduces dopamine release (Reimann, 1983), and inactivation of the VTA or systemic delivery of dopamine antagonists prevents cocaine-induced reinstatement and associated synaptic plasticity (Shen et al., 2014). A predominant influence on dopamine rather than glutamate release could explain gabapentin's preferential effects on cocaine or cocaine plus cue-primed reinstatement compared with conditioned cues as a noncontingent cocaine injection causes greater release of dopamine compared with cue (Ito et al., 2000).

Despite the above-mentioned evidence, we cannot discount the possible contribution of dendritically expressed $\alpha_{2} \delta$-1 coupling to primarily postsynaptic LTCCs. Several studies have linked LTCC-mediated signaling to cocaine-induced changes in AMPA receptor plasticity observed in NAc that are essential for cocaine-induced reinstatement (Pierce et al., 1998; Anderson et al., 2008). Thus, increased $\alpha_{2} \delta-1$ in concert with LTCCs may contribute to the dynamic excitability of NAc neurons whereby the intrinsic membrane excitability is decreased at early withdrawal, restored after protracted withdrawal, and ultimately augmented upon re-exposure to cocaine (Mu et al., 2010). Finally, calcium channel-independent mechanisms may play a role in 

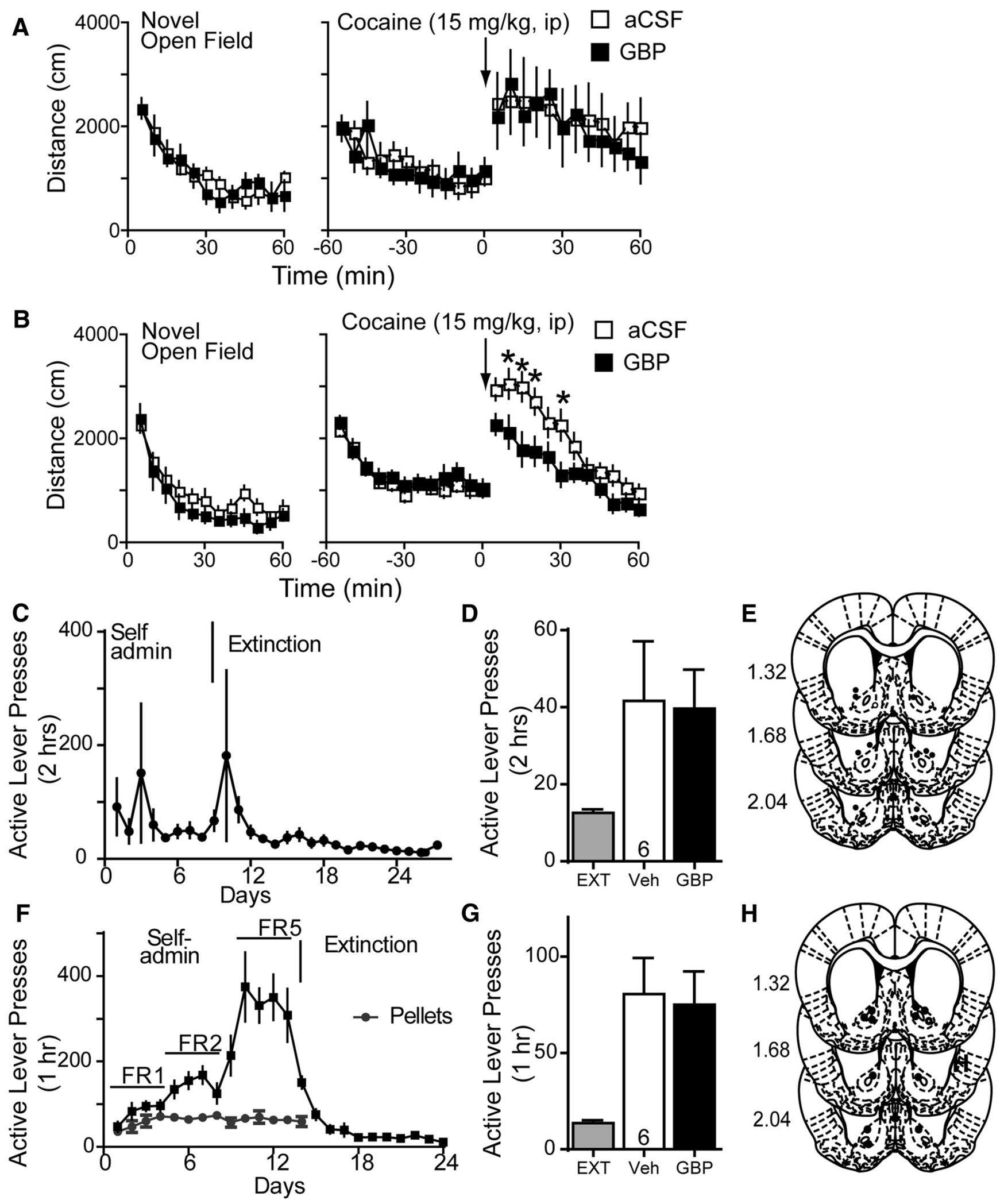

Figure 4. Gabapentin control experiments. $A, 10 \mu \mathrm{g} /$ side microinjection of gabapentin did not alter basal locomotor activity or cocaine-induced hyperactivity (10 mg/kg, i.p., cocaine injection at arrow). $\boldsymbol{B}, 33 \mu \mathrm{g} /$ side GBP did not alter basal locomotor activity but blunted cocaine-induced hyperactivity. $\boldsymbol{C}$, Active lever pressing during self-administration and extinction training for cocaine reinstatement in $\boldsymbol{D}$. D, Microinjection of GBP (10 $\mu \mathrm{g} / \mathrm{side})$ in dorsal striatum has no effect on cocaine-induced reinstatement. $\boldsymbol{E}$, Histological verification of injection placement in dorsal striatum corresponding to data in $\mathbf{D}$; numbers refer to millimeters rostral to bregma. $\boldsymbol{F}$, Active lever pressing during self-administration and extinction training for sucrose reinstatement in $\mathbf{G}$. $\mathbf{G}$, Microinjection of GBP (10 $\mu \mathrm{g} / \mathrm{side})$ in NAcore had no effect on sucrose pellet plus cue-primed reinstatement of sucrose seeking. $\boldsymbol{H}$, Histological verification of injection placement in NAcore corresponding to data in $\mathbf{G} .{ }^{*} p<0.05$, comparing GBP with aCSF microinjection using a Bonferroni's post hoc analysis. 
gabapentin's effects since $\alpha_{2} \delta$-1 stimulation by TSPs promotes the formation of excitatory synapses (Eroglu et al., 2009). Withdrawal from chronic cocaine is associated with LTP-like increases in dendritic spine density and diameter with a further LTP-like augmentation of synaptic strength accompanying reinstated cocaine seeking (Gipson et al, 2013; Shen et al., 2014). Therefore gabapentin's inhibition of TSP $/ \alpha_{2} \delta$-1-mediated excitatory synaptogenesis may contribute to its ability to reduce cocaine reinstatement, although the LTP-like changes occur after reinstatement elicited by either cues or cocaine injection. While our finding elevated TSP-1 in NAcore of cocaine-trained subjects is consistent with this possibility, it is also worth noting that TSP-1 catabolic products can interact directly with integrins independent of binding $\alpha_{2} \delta$-1. A peptide modulator used to disrupt this interaction also inhibits cocaine-induced, but not cue-induced, reinstatement of cocaine seeking (Wiggins et al., 2011). This supports an involvement of TSP-1 binding to integrins.

In accord with our present findings, Kurokawa et al. showed that intracerebroventricular delivery of gabapentin blocks methamphetamine-induced sensitization and conditioned place preference ( 2011), but other studies have examined the effects of a single systemic injection of gabapentin on cocaine self-administration or cocaine-primed reinstatement with negative results (Filip et al., 2007; Peng et al., 2008). The differing effects in these studies may be related to the poor bioavailability of systemic GBP to the brain (Bockbrader et al., 2010). This is supported by reductions in cocaine seeking elicited by conditioned cues and pharmacological stressors after systemic administration of another $\alpha_{2} \delta-1$ antagonist, pregabalin, with improved bioavailability (de Guglielmo et al., 2013). Perhaps due to these bioavailability issues, GBP has had mixed results in clinical addiction studies as well (Minozzi et al., 2008; Mason et al., 2009, 2012). Our study highlights the potential importance of cocaineinduced alterations in $\alpha_{2} \delta$-1 in NAcore, and the efficacy of GBP on only cocaine-induced reinstatement suggests that its utility in controlling cocaine relapse will be in combination with other treatments.

\section{References}

Anderson SM, Famous KR, Sadri-Vakili G, Kumaresan V, Schmidt HD, Bass CE, Terwilliger EF, Cha JH, Pierce RC (2008) CaMKII: a biochemical bridge linking accumbens dopamine and glutamate systems in cocaine seeking. Nat Neurosci 11:344-353. CrossRef Medline

Bockbrader HN, Wesche D, Miller R, Chapel S, Janiczek N, Burger P (2010) A comparison of the pharmacokinetics and pharmacodynamics of pregabalin and gabapentin. Clin Pharmacokinet 49:661-669. CrossRef Medline

de Guglielmo G, Cippitelli A, Somaini L, Gerra G, Li H, Stopponi S, Ubaldi M, Kallupi M, Ciccocioppo R (2013) Pregabalin reduces cocaine selfadministration and relapse to cocaine seeking in the rat. Addict Biol 18: 644-653. CrossRef Medline

Dennis M, Scott CK (2007) Managing addiction as a chronic condition. Addict Sci Clin Pract 4:45-55. CrossRef Medline

Dolphin AC (2012) Calcium channel auxiliary $\alpha 2 \delta$ and $\beta$ subunits: trafficking and one step beyond. Nat Rev Neurosci 13:542-555.

Epstein DH, Preston KL, Stewart J, Shaham Y (2006) Toward a model of drug relapse: an assessment of the validity of the reinstatement procedure. Psychopharmacology 189:1-16. CrossRef Medline

Eroglu C, Allen NJ, Susman MW, O'Rourke NA, Park CY, Ozkan E, Chakraborty C, Mulinyawe SB, Annis DS, Huberman AD, Green EM, Lawler J, Dolmetsch R, Garcia KC, Smith SJ, Luo ZD, Rosenthal A, Mosher DF, Barres BA (2009) Gabapentin receptor $\alpha 2 \delta$-1 is a neuronal thrombospondin receptor responsible for excitatory CNS synaptogenesis. Cell 139:380-392. CrossRef Medline

Filip M, Frankowska M, Zaniewska M, Gołda A, Przegaliński E, Vetulani J (2007) Diverse effects of GABA-mimetic drugs on cocaine-evoked self- administration and discriminative stimulus effects in rats. Psychopharmacology 192:17-26. CrossRef Medline

Gee NS, Brown JP, Dissanayake VU, Offord J, Thurlow R, Woodruff GN (1996) The novel anticonvulsant drug, gabapentin (Neurontin), binds to the subunit of a calcium channel. J Biol Chem 271:5768-5776. CrossRef Medline

Gipson CD, Kupchik YM, Shen H, Reissner KJ, Thomas CA, Kalivas PW (2013) Relapse induced by cues predicting cocaine depends on rapid, transient synaptic potentiation. Neuron 77:867-872. CrossRef Medline

Hayashida S, Katsura M, Torigoe F, Tsujimura A, Ohkuma S (2005) Increased expression of L-type high voltage-gated calcium channel $\alpha 1$ and $\alpha 2 / \delta$ subunits in mouse brain after chronic nicotine administration. Brain Res Mol Brain Res 135:280-284. CrossRef Medline

Ito R, Dalley JW, Howes SR, Robbins TW, Everitt BJ (2000) Dissociation in conditioned dopamine release in the nucleus accumbens core and shell in response to cocaine cues and during cocaine-seeking behavior in rats. J Neurosci 20:7489-7495. Medline

Kalivas PW (2009) The glutamate homeostasis hypothesis of addiction. Nat Rev Neurosci 10:561-572. CrossRef Medline

Katsura M, Shibasaki M, Hayashida S, Torigoe F, Tsujimura A, Ohkuma S (2006) Increase in expression of alpha1 and alpha2/delta1 subunits of L-type high voltage-gated calcium channels after sustained ethanol exposure in cerebral cortical neurons. J Pharmacol Sci 102:221-230. CrossRef Medline

Kawamoto EM, Vivar C, Camandola S (2012) Physiology and pathology of calcium signaling in the brain. Front Pharmacol 3:61. CrossRef Medline

Kupchik YM, Moussawi K, Tang XC, Wang X, Kalivas BC, Kolokithas R, Ogburn KB, Kalivas PW (2012) The effect of N-acetylcysteine in the nucleus accumbens on neurotransmission and relapse to cocaine. Biol Psychiatry 71:978-986. CrossRef Medline

Kurokawa K, Shibasaki M, Mizuno K, Ohkuma S (2011) Gabapentin blocks methamphetamine-induced sensitization and conditioned place preference via inhibition of $\alpha 2 / \delta$-1 subunits of the voltage-gated calcium channels. Neuroscience 176:328-335. CrossRef Medline

Lee NV, Sato M, Annis DS, Loo JA, Wu L, Mosher DF, Iruela-Arispe ML (2006) ADAMTS1 mediates the release of antiangiogenic polypeptides from TSP1 and 2. EMBO J 25:5270-5283. CrossRef Medline

Mason BJ, Light JM, Williams LD, Drobes DJ (2009) Proof-of-concept human laboratory study for protracted abstinence in alcohol dependence: effects of gabapentin. Addict Biol 14:73-83. CrossRef Medline

Mason BJ, Crean R, Goodell V, Light JM, Quello S, Shadan F, Buffkins K, Kyle M, Adusumalli M, Begovic A, Rao S (2012) A proof-of-concept randomized controlled study of gabapentin: effects on cannabis use, withdrawal and executive function deficits in cannabis-dependent adults. Neuropsychopharmacology 37:1689-1698. CrossRef Medline

Minozzi S, Amato L, Davoli M, Farrell MF, Lima Reisser AA, Pani PP, Silva de Lima M, Soares B, Vecchi S (2008) Anticonvulsants for cocaine dependence. Cochrane Database Syst Rev 16:CD006754. CrossRef Medline

Mu P, Moyer JT, Ishikawa M, Zhang Y, Panksepp J, Sorg BA, Schlüter OM, Dong Y (2010) Exposure to cocaine dynamically regulates the intrinsic membrane excitability of nucleus accumbens neurons. J Neurosci 30: 3689-3699. CrossRef Medline

Nasif FJ, Hu XT, White FJ (2005) Repeated cocaine administration increases voltage-sensitive calcium currents in response to membrane depolarization in medial prefrontal cortex pyramidal neurons. J Neurosci 25:3674-3679. CrossRef Medline

Paxinos G, Watson C (2005) The rat brain in stereotaxic coordinates. Amsterdam: Elsevier Academic.

Peng XQ, Li X, Li J, Ramachandran PV, Gagare PD, Pratihar D, Ashby CR Jr, Gardner EL, Xi ZX (2008) Effects of gabapentin on cocaine selfadministration, cocaine-triggered relapse and cocaine-enhanced nucleus accumbens dopamine in rats. Drug Alcohol Depend 97:207-215. CrossRef Medline

Pierce RC, Quick EA, Reeder DC, Morgan ZR, Kalivas PW (1998) Calciummediated second messengers modulate the expression of behavioral sensitization to cocaine. J Pharmacol Exp Ther 286:1171-1176. Medline

Quintero JE, Dooley DJ, Pomerleau F, Huettl P, Gerhardt GA (2011) Amperometric measurement of glutamate release modulation by gabapentin and pregabalin in rat neocortical slices: role of voltage-sensitive $\mathrm{Ca} 2+$ $\alpha 2 \delta$-1 subunit. J Pharmacol Exp Ther 338:240-245. CrossRef Medline

Rajadhyaksha AM, Kosofsky BE (2005) Psychostimulants, L-type calcium 
channels, kinases, and phosphatases. Neuroscientist 11:494-502. CrossRef Medline

Reimann W (1983) Inhibition by GABA, baclofen and gabapentin of dopamine release from rabbit caudate nucleus: are there common or different sites of action? Eur J Pharmacology 94:341-344. CrossRef

Reissner KJ, Uys JD, Schwacke JH, Comte-Walters S, Rutherford-Bethard JL, Dunn TE, Blumer JB, Schey KL, Kalivas PW (2011) AKAP signaling in reinstated cocaine seeking revealed by iTRAQ proteomic analysis. J Neurosci 31:5648-5658. CrossRef Medline

Schierberl K, Hao J, Tropea TF, Ra S, Giordano TP, Xu Q, Garraway SM, Hofmann F, Moosmang S, Striessnig J, Inturrisi CE, Rajadhyaksha AM (2011) Cav1.2 L-type Ca2 + channels mediate cocaine-induced GluA1 trafficking in the nucleus accumbens, a long-term adaptation dependent on ventral tegmental area cav1.3 channels. J Neurosci 31:13562-13575. CrossRef Medline
Shaham Y, Shalev U, Lu L, De Wit H, Stewart J (2003) The reinstatement model of drug relapse: history, methodology and major findings. Psychopharmacology 168:3-20. CrossRef Medline

Shen HW, Gipson CD, Huits M, Kalivas PW (2014) Prelimbic cortex and ventral tegmental area modulate synaptic plasticity differentially in nucleus accumbens during cocaine-reinstated drug seeking. Neuropsychopharmacology 39:1169-1177. CrossRef Medline

Uchitel OD, Di Guilmi MN, Urbano FJ, Gonzalez-Inchauspe C (2010) Acute modulation of calcium currents and synaptic transmission by gabapentinoids. Channels 4:490-496. Medline

Wiggins A, Smith RJ, Shen HW, Kalivas PW (2011) Integrins modulate relapse to cocaine-seeking. J Neurosci 31:16177-16184. CrossRef Medline

Wolf ME (2010) The Bermuda Triangle of cocaine-induced neuroadaptations. Trends Neurosci 33:391-398. CrossRef Medline 